\title{
Sensitivity Analysis of Factors Influencing the Anchorage Force of Soil Anchor Rods Based on the Orthogonal Experiment - ANN
}

\author{
B.Q. Wang, J.B. Hao \\ School of Geology Engineering and Geomatics \\ Chang'an University \\ Xi'an, China
}

\begin{abstract}
Based on the BP algorithm of artificial neural network (ANN), an intelligent model which is used to predict the anchorage force of soil anchor rods is established in this article, under the comprehensive consideration of the anchor rod diameter, strength of the grouting body, length of anchoring segment, bore diameter, inclination angle of the anchor rod, and other factors. Combining with the in-situ test data of the anchor rod reinforcement engineering, the network is trained and the errors are analyzed. Thus it verifies the applicability and feasibility of the method. Extended calculations are conducted by using the well-trained intelligent forecast model. Through application of orthogonal table test theory, 25 groups of tests are designed to analyze the sensitivity of influencing factors on the anchorage force of anchor rods in the soil. The results show that: the sensitivity of influencing factors on the anchorage force of soil anchor rods, in a descending order, is the length of anchoring segment, strength of the grouting body, anchor rod diameter, bore diameter, inclination angle of anchor rod. The results can provide reference for the practical application of the same reinforcement engineering.
\end{abstract}

Keywords-soil anchor rod; anchorage force; orthogonal test; artificial neural network (ANN); sensitivity analysis

\section{INTRODUCTION}

The anchorage force of soil anchor rods depend on multiple factors such as the length of the anchoring segment, anchor rod diameter, hole diameter, strength of the grouting-body, inclination angle of anchor rods, soil properties and other factors. These factors inevitably have some uncertainties [1]. How much the influence of the possible swinging range of these uncertain factors on the soil anchor rod's anchorage force, as well as to which factor the anchorage force is the most sensitive, are often important concerns for an anchoring engineering.

In 1986, Hohenbichler [2] conducted a study of the sensitivity of reliability on random variables. Then Madsen [3], Bjerager [4] and Karamchandani [5] et al further studied that question. There was at present less research on the sensitivity of parameters of anchoring engineering in China. Reported articles are mainly confined to the analysis of sensitivity of various parameters on stability and deformation of anchoring engineering [6-9]. There are few studies about sensitivity of soil anchor rod anchorage force [10-12], even almost none. The existing research methods for sensitivity have been confined to the finite element method (FEM). The obvious drawback of this method is that the amount of calculation is very large if too many parameters are required. On the other hand it is difficult to determine the combination of multiple parameters.

Based on the in-situ test trials of the anchorage force of anchor rods in the loess soil at a site in Xi'an, under the comprehensive consideration of the anchorage force's influencing factors such as length of anchoring segment, anchor rod diameter, inclination angle, the strength of the grouting-body, and the hole diameter, an intelligent model of anchorage force prediction has been established by using of error back-propagation (BP) algorithm of artificial neural networks (ANN) and MATLAB ANN toolbox [13-14]. On this basis, the sensitivity of the anchorage force to various influencing factors is analyzed, by adopting the orthogonal table test [15] theory. It provides reference for the practical application of the same reinforcement engineering.

\section{Neural Network Design Based ON The ORTHOGONAL EXPERIMENT}

Because of its good self-learning, self-organizing, associative memory ability and strong fault tolerance, neural network is particularly suitable for dealing with a variety of nonlinear problems. At present, there are already examples successfully applied to supporting the bearing capacity projection. One of the most critical problems is the selection of network structure in the applications of neural networks. It is equivalent to the determination of the unknown model forms. For this, there has been no definite method to be found up to now. It is accepted that the best network structure is those who are consistent with the given sample(s), and is the simplest one (with the smallest scale). It's mainly because of the unique features or less probability of noise in the learning and training data of the small scale neural networks. Thus it has better generalization of the new data; at the same time, it's easy to understand network rules and extract knowledge, being conducive to achieving the goal.

In order to obtain the smallest network that meets the performance requirements, the author puts forward the design method of the neural network based on the orthogonal test in this paper. The method can be started from any network, and improve the network structure by using the principle of orthogonal test, improve the network performance, until finally the better (or optimal) neural network is designed. And 
we can obtain the optimal decision by utilizing extreme difference analysis or variance analysis method of the orthogonal test, revealing the interaction strength between layers of the neural network.

\section{III.PRoJection Model of the ANCHORAGE ForCE OF SOIL ANCHOR RODS}

\section{A. Establishment of BP Neural Network Projection Model}

(1)The input layer and determination of its parameters

The node numbers of neurons of the input layer in the neural network model are decided by the numbers of factors that affect the output layer. According to the mechanical characteristics of soil anchor rods, there are five factors considered in this paper: (1) length of anchoring segment, (2) anchor rod diameter, (3)hole diameter, (4) strength of grouting body, (5)inclination angle of anchor rod; the number of nodes in the input layer is 5 . The output layer is the predicted value of the anchorage force of soil anchor rods, with the node number of $\mathrm{m}=1$.

(2)Determination of parameters of the hidden layer

According to Kolmogorov theorem, under the conditions of a rational structure and appropriate weight, the tree-layer feed-forward network can approximate any continuous function. The tree-layer BP network established in this paper includes an input layer, a hidden layer, and an output layer. It can complete any n-dimensional to m-dimensional mapping, in which the node numbers of the hidden layer is $2 n+1=11$.

(3)The prediction model

According to the node numbers of the determined input layers, hidden layers and output layers, and the numbers of the hidden layers, the forecast model structured in this paper is as shown in Figure I , is BP model of 5 - 11 - 1.

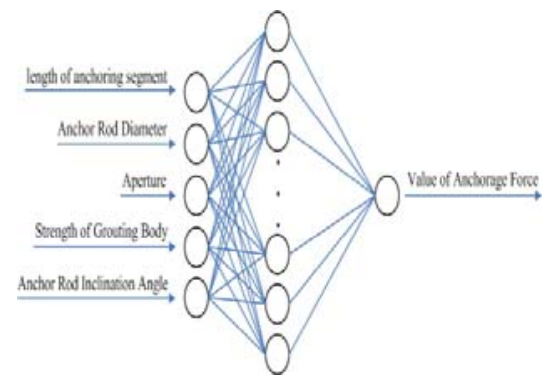

FIGURE I. NEURAL NETWORK MODEL TO PREDICT THE ANCHORAGE FORCE OF SOIL ANCHOR RODS.

\section{(4)The excitation function}

The neuronal excitation function adopted by this model is an asymmetric S-type function, one of sigmoid functions,

$$
f(x)=1 / 1+e^{-x}
$$

\section{B. Model Training and Inspection}

(1)Training samples obtained from on-site in-situ test

This paper selected 10 sets of data obtained from the in-situ test of soil anchor rods as learning samples, and considered respectively the impact of various factors, such as the anchoring length, anchor rod diameter, hole diameter, strength of grouting body, and inclination angle of anchor rod, upon the anchorage force, as shown in Table I .

TABLE I. LEARNING SAMPLES OF THE FORECAST MODEL.

\begin{tabular}{|c|c|c|c|c|c|c|}
\hline No. & $\begin{array}{c}\text { Anchoring } \\
\text { length } \\
\text { /mm }\end{array}$ & $\begin{array}{l}\text { Anchor } \\
\text { rod } \\
\text { diameter } \\
/ \mathrm{mm}\end{array}$ & $\begin{array}{l}\text { Aperture } \\
\text { /mm }\end{array}$ & $\begin{array}{l}\text { Anchor } \\
\text { Rod } \\
\text { Inclination } \\
\text { angle } \\
\text { / }^{\circ}\end{array}$ & $\begin{array}{l}\text { Strength } \\
\text { of } \\
\text { Grouting } \\
\text { Body } \\
/ \mathrm{MPa}\end{array}$ & $\begin{array}{c}\text { Value of } \\
\text { Anchorage } \\
\text { force } \\
\text { /KN }\end{array}$ \\
\hline 1 & 5 & 32 & 100 & 15 & 2.0 & 82 \\
\hline 2 & 6 & 32 & 100 & 10 & 3.0 & 85 \\
\hline 3 & 8.9 & 20 & 100 & 10 & 2.0 & 85 \\
\hline 4 & 9 & 25 & 130 & 15 & 2.0 & 103 \\
\hline 5 & 9 & 32 & 130 & 15 & 3.0 & 120 \\
\hline 6 & 12 & 25 & 130 & 15 & 3.0 & 140 \\
\hline 7 & 12 & 28 & 130 & 15 & 3.0 & 140 \\
\hline 8 & 12 & 32 & 130 & 15 & 3.0 & 220 \\
\hline
\end{tabular}

(2)The network training of the samples

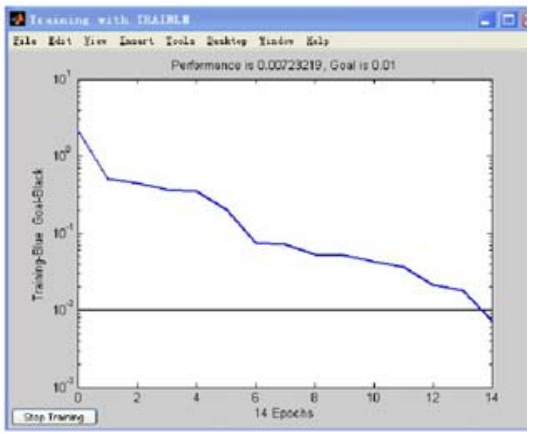

FIGURE II. CURVE OF ERRORS VARYING WITH THE TRAINING FREQUENCY.

Before training of the sample, in order to accelerate the convergence speed of the network and enhance the computational efficiency, using the normalized function premnmx offered by MATLAB neural network toolbox, we normalize the input matrix and output matrix so that the processed data between $[-1,1]$. The constructed model is trained by using the normalized data.

The training function adopts the default "trainlm" of the MATLAB neural network system. The training shows that the interval frequency (spacing number of times) is set to be 50 . The maximum number of cycles is set to be 1000 . The performance target value is set to be 0.01 . The learning coefficient is set to be 0.01 . When the number of cumulative training steps is up to 14 steps, the training error converges to the target precision of 0.01 . The curves of the errors varying with training frequency are as shown in Figure II. After the end of the training, the original sample data are predicted to generate predicted values. The predicted values are anti-normalized to get the final predicted value. (3) Predicted results and error analysis 
TABLE II. PREDICTED RESULTS AND ERRORS.

\begin{tabular}{|c|c|c|c|c|c|c|c|c|c|c|}
\hline No. & $\begin{array}{c}\text { Anchoring } \\
\text { length } \\
\text { /mm }\end{array}$ & $\begin{array}{l}\text { Anchor } \\
\text { rod } \\
\text { diameter } \\
/ \mathrm{mm}\end{array}$ & $\begin{array}{l}\text { Aperture } \\
/ \mathrm{mm}\end{array}$ & $\begin{array}{l}\text { Strength } \\
\text { Of } \\
\text { Grouting } \\
\text { Body } \\
\text { /KN }\end{array}$ & $\begin{array}{c}\text { Anchor } \\
\text { Rod } \\
\text { Inclination } \\
\text { angle } \\
\left(^{\circ}\right)\end{array}$ & $\begin{array}{l}\text { Measured } \\
\text { Value of } \\
\text { Anchorage } \\
\text { force } \\
\text { /KN }\end{array}$ & $\begin{array}{l}\text { Predicted } \\
\text { value of } \\
\text { Anchorage } \\
\text { force } \\
\text { /KN }\end{array}$ & $\begin{array}{c}\text { Absolute } \\
\text { error }\end{array}$ & $\begin{array}{c}\text { Relative } \\
\text { Error } \\
\%\end{array}$ & $\begin{array}{c}\text { Average } \\
\text { relative } \\
\text { Error } \\
\%\end{array}$ \\
\hline 1 & 8.9 & 20 & 100 & 2.0 & 10 & 85 & 86.653 & 1.653 & $\begin{array}{c}1.944 \\
7\end{array}$ & \\
\hline 2 & 9 & 25 & 130 & 2.0 & 15 & 103 & 104.224 & 1.224 & $\begin{array}{c}1.188 \\
3\end{array}$ & \\
\hline 3 & 9 & 32 & 130 & 3.0 & 15 & 120 & 124.568 & 4.568 & $\begin{array}{c}3.806 \\
7\end{array}$ & 1.95 \\
\hline 4 & 12 & 25 & 130 & 3.0 & 15 & 140 & 138.217 & -1.783 & $\begin{array}{c}1.273 \\
6\end{array}$ & \\
\hline 5 & 12 & 28 & 130 & 3.0 & 15 & 140 & 142.186 & 2.186 & $\begin{array}{c}1.561 \\
4\end{array}$ & \\
\hline
\end{tabular}

After the end of the training, the author constructed model of the anchor rod bearing capacity prediction reaches the specified performance targets. The inherent nonlinear mapping relationship is stored in each layer of the network offered by the samples. Thus it defined the weights of various input and output layers and their thresholds. In order to analyze the accuracy of prediction of the established network model, five groups of in-situ test data are firstly selected as the test samples. Using the sim function to generate predicted values; then use the postmnmx function to anti-normalize the predicted values, to get the final forecasted values. Finally, compare the predicted values and in-situ test values, as shown in Table 2. The results show that the average relative error of the model predicted results is $1.95 \%$. It can meet the project needs, indicating that the model has certain feasibility and practicality in forecast of anchorage force of soil anchor rods.

\section{IV.SENSITIVITY ANALYSIS OF FACTORS INFLUENCING THE ANCHORAGE FORCE OF SOIL ANCHOR RODS}

\section{A. Selection of the Orthogonal Table}

TABLE III. THE LEVEL TABLE OF THE FACTORS.

\begin{tabular}{cccccc}
\hline $\begin{array}{c}\text { Factors Anchoring } \\
\text { level }\end{array}$ & length & diameter & Aperture & $\begin{array}{c}\text { Anchor rod } \\
\text { inclination }\end{array}$ & $\begin{array}{c}\text { Grouting } \\
\text { strength }\end{array}$ \\
\hline 1 & $-20 \%$ & $-20 \%$ & $-20 \%$ & $-20 \%$ & $-20 \%$ \\
2 & $-10 \%$ & $-10 \%$ & $-10 \%$ & $-10 \%$ & $-10 \%$ \\
3 & $0 \%$ & $0 \%$ & $0 \%$ & $0 \%$ & $0 \%$ \\
4 & $10 \%$ & $10 \%$ & $10 \%$ & $10 \%$ & $10 \%$ \\
5 & $20 \%$ & $20 \%$ & $20 \%$ & $20 \%$ & $20 \%$ \\
\hline
\end{tabular}

TABLE IV. ORTHOGONAL MARSHALL TEST PROGRAM.

\begin{tabular}{|c|c|c|c|c|c|}
\hline Test No. & $\begin{array}{c}\text { Anchoring } \\
\text { length } \\
\text { level }\end{array}$ & $\begin{array}{c}\text { Anchor rod } \\
\text { diameter } \\
\text { level }\end{array}$ & $\begin{array}{c}\text { Aperture } \\
\text { level }\end{array}$ & $\begin{array}{l}\text { Anchor rod } \\
\text { inclination } \\
\text { level }\end{array}$ & $\begin{array}{l}\text { Grouting } \\
\text { Strength } \\
\text { level }\end{array}$ \\
\hline 1 & 1 & 1 & 1 & 1 & 1 \\
\hline 2 & 1 & 2 & 2 & 2 & 2 \\
\hline 3 & 1 & 3 & 3 & 3 & 3 \\
\hline 4 & 1 & 4 & 4 & 4 & 4 \\
\hline 5 & 1 & 5 & 5 & 5 & 5 \\
\hline 6 & 2 & 1 & 2 & 3 & 4 \\
\hline 7 & 2 & 2 & 3 & 4 & 5 \\
\hline 8 & 2 & 3 & 4 & 5 & 1 \\
\hline
\end{tabular}

$\begin{array}{cccccc}9 & 2 & 4 & 5 & 1 & 2 \\ 10 & 2 & 5 & 1 & 2 & 3 \\ 11 & 3 & 1 & 3 & 5 & 2 \\ 12 & 3 & 2 & 4 & 1 & 3 \\ 13 & 3 & 3 & 5 & 2 & 4 \\ 14 & 3 & 4 & 1 & 3 & 5 \\ 15 & 3 & 5 & 2 & 4 & 1 \\ 16 & 4 & 1 & 4 & 2 & 5 \\ 17 & 4 & 2 & 5 & 3 & 1 \\ 18 & 4 & 3 & 1 & 4 & 2 \\ 19 & 4 & 4 & 2 & 5 & 3 \\ 20 & 4 & 5 & 3 & 1 & 4 \\ 21 & 5 & 1 & 5 & 4 & 3 \\ 22 & 5 & 2 & 1 & 5 & 4 \\ 23 & 5 & 3 & 2 & 1 & 5 \\ 24 & 5 & 4 & 3 & 2 & 1 \\ 25 & 5 & 5 & 4 & 3 & 2\end{array}$

Orthogonal testing is a designing method of tests that utilizes the orthogonal principle and mathematical statistics, selects typical and representative test points from a large number of test points, arranges reasonably and scientifically the tests by application of the orthogonal tables, and obtains the optimal results with the number of times as less as possible. The conditions that need to be inspected and/or can be controlled in the experiment are called factor or factors. Each status or grade of a factor is called a level of a factor.

According to the principle of orthogonal table selection, the level number of factors determined in this paper is 5; the number of factors is 5 , too, being respectively the anchoring length, anchor rod diameter, hole diameter, the strength of the grouting body, and anchor rod inclination angle. Table 3 is the level table of the factors selected.

For the five factors five levels, they require 3125 trials if full-scale testing; when using orthogonal table L25 they only need 25 Marshall tests. TableIV is the L25 orthogonal table selected according to the level numbers and factor numbers.

The 5 columns of data in the table are respectively five indicators that affect anchorage force of soil anchor rods. The table is arranged in any order. 
TABLE V. TABLE OF PREDICTION RESULTS

\begin{tabular}{|c|c|c|c|c|c|c|c|c|c|}
\hline $\begin{array}{l}\text { Test } \\
\text { No. }\end{array}$ & $\begin{array}{l}\text { Prediction } \\
\text { results }\end{array}$ & $\begin{array}{l}\text { Test } \\
\text { No. }\end{array}$ & $\begin{array}{l}\text { Prediction } \\
\text { results }\end{array}$ & $\begin{array}{l}\text { Test } \\
\text { No. }\end{array}$ & $\begin{array}{l}\text { Prediction } \\
\text { results }\end{array}$ & $\begin{array}{l}\text { Test } \\
\text { No. }\end{array}$ & $\begin{array}{l}\text { Prediction } \\
\text { results }\end{array}$ & $\begin{array}{l}\text { Test } \\
\text { No. }\end{array}$ & $\begin{array}{c}\text { Prediction } \\
\text { results }\end{array}$ \\
\hline 1 & 102.956 & 6 & 117.33 & 11 & 100.382 & 16 & 142.617 & 21 & 164.879 \\
\hline 2 & 110.749 & 7 & 113.783 & 12 & 99.477 & 17 & 120.605 & 22 & 190.099 \\
\hline 3 & 111.526 & 8 & 110.008 & 13 & 99.748 & 18 & 117.374 & 23 & 117.244 \\
\hline 4 & 137.677 & 9 & 115.17 & 14 & 100.821 & 19 & 141.691 & 24 & 119.178 \\
\hline 5 & 115.347 & 10 & 124.002 & 15 & 100.837 & 20 & 232.374 & 25 & 168.842 \\
\hline
\end{tabular}

TABLE VI. ORTHOGONAL TEST TABLE.

\begin{tabular}{cccccc}
\hline Level & $\begin{array}{c}\text { Anchoring } \\
\text { length }\end{array}$ & $\begin{array}{c}\text { Anchor rod } \\
\text { diameter }\end{array}$ & Aperture & $\begin{array}{c}\text { Anchor rod } \\
\text { inclination }\end{array}$ & $\begin{array}{c}\text { Grouting } \\
\text { strength }\end{array}$ \\
\hline The first level average & 115.651 & 125.6328 & 127.0504 & 133.4442 & 110.7168 \\
he second level averag & 116.0586 & 126.9426 & 117.5702 & 119.2588 & 122.5034 \\
The third level average & 100.253 & 111.18 & 136.2486 & 123.8248 & 128.315 \\
The fourth level averagt & 150.9322 & 122.9074 & 131.7242 & 126.91 & 155.4456 \\
The fifth level average & 152.0484 & 148.2804 & 123.1498 & 131.5054 & 117.9624 \\
$\begin{array}{c}\text { Extreme differences } \\
\text { Sequence of extreme }\end{array}$ & 51.7954 & 37.1004 & 18.6784 & 14.1854 & 44.7288 \\
differences & 1 & 3 & 4 & 5 & 2 \\
\hline
\end{tabular}

The trained network has certain feasibility and practicality in anchorage force projection. Now we take a certain reinforcement project as an example, predict the anchorage force of soil anchor rods, and analyze the sensitivity.

Design example: the length of anchoring segment is $9 \mathrm{~m}$; diameter $32 \mathrm{~mm}$; hole diameter $130 \mathrm{~mm}$; grouting strength 3.0Mpa; anchor rod inclination $15^{\circ}$.

In accordance with the selected L25 orthogonal table, we change the levels in table $\mathrm{V}$ and make up them to form the 25 trial samples in TableVI.

To predict respectively the above 25 trial samples by using the trained network model. The results are shown in Table V .

Averaging the results of five experiments of the same level of each factor, the average value of each index can be obtained for each factor at different levels. Working out the difference between the maximum and minimum values of indicators of the same factor at different levels, the extreme differences corresponding to the factor variation can be obtained, as shown in TableVI.

The experimental results showed that: the sensitivity of factors influencing anchorage force of soil anchor rods were successively the anchoring length, grouting body strength, anchor rod diameter, hole diameter, and anchor rod inclination angle.

\section{CONCLUSION}

(1) Artificial neural network (ANN) has good self-adaptability, self-organization and strong learning, associative memory, fault tolerance and anti-interference ability and so on. Through introduction of the ANN into the anchoring system, you can fully consider many factors that influence the anchorage force of anchor rods, and achieve the intelligent prediction of anchorage force.

(2) The projection model of the anchorage force of anchor rods established in this paper by utilizing ANN makes a highly nonlinear mapping set up between various factors affecting the anchor rods and its anchorage force. Combined with the in-situ test data of soil anchor rod reinforcement, we have verified the feasibility and applicability of ANN in this field, providing a new approach or method reference for projections of other similar anchorage force.

(3) In this paper, we reveal the strength of the interaction between the layers of the neural network by adopting the combination of the ANN with the orthogonal trial design, and can achieve a good sensitivity analysis of influencing factors of the anchorage force of anchor rods. The analysis results showed that: the sensitivity of influencing factors on the anchorage force of soil anchor rods, in a descending order, is the anchoring length, grouting body strength, anchor rod diameter, hole diameter, anchor rod inclination angle.

\section{ACKNOWLEDGMENTS}

The work in this paper were supported by the National Natural Science of China through Grants 41440021, by the Special Fund for Basic Scientific Research of Central Colleges, Chang'an University through Grant 2014G1261049 and 2013G22610, and by the Geotechnical Engineering Open Laboratory of Ministry of Land and Resources.

\section{REFERENCES}

[1] Liang-kui CHENG. Present status and development of ground anchorages. China Civil Engineering Journal, 34(3): 7-8, 2001

[2] Hohenbichler M, Rackwtz R. Sensitivities and importance measures in structural reliability[J]. Civil Eng. System, (3): 203 209, 1986

[3] Madsen H O, Krenk S, Lind N C. Methods of Structural Safety[M] New York: Springer Verlag, 150 200, 1986

[4] Bjerager P, Krenk S. Parameter sensitivity in first order reliability analysis[J] . J of Eng. Mech., 115( 7) : 1 577 1582, 1989

[5] Karamchandani A, Cornell C A. Sensitivity estimation within first and second order reliability methods [J] . Struct. Safety, 11: 97 105, 1992

[6] Lewis M, Rimas P, Doug M. Determination of physical properties of cable bolts in cement grout pull tests using instrument King 
Wires. In: Canadian Institute of Mining Annual Conference, Vancouver, 2002

[7] Bang-shu XU, Ri-cheng LIU ,Lian-xiang LI, Ming GONG, Yu-kui WANG. Study of slope deformation and parameters sensitivity in supporting design of composite soil nailing wall [J]. Rock and Soil Mechanics, 32(S2): 393-400, 2011

[8] Hai-lin YE, Run-qiu HUANG, Ying-ren ZHENG, Xiu-li DU, An-hong LI. Numerical simulation of pressure-type anchor based on energy principle[J]. Chinese Journal of Geotechnical Engineering, 32(9): 1374-1379, 2010

[9] Ai-jun YAO, Yong-hua SU. A method for stability of slope engineering with complicated rock-mass[J]. China Civil Engineering Journal, 36(11): 34-37, 2003

[10] Fu-qiang GAO, Xing-ku WANG. Analysis on sensitive normal test of bolt support parameters form in ing gateway [J]. Coal Science and Technology, 35(11): 68-72, 2007

[11] Xia SU, Zhong-kui LI. Numerical study of the influence factors of anchorage under tension[J].Engineering Mechanics, 23(2): 97-102, 2006

[12] Dong-bo LI, Dong ZHAO, Jun HUA. Anchorage force prediction for the cfrp-bamboo bolt based on artificial neural network [J]. Mechanics in Engineering , 35(2):40-45, 2013

[13] Li-cheng JIAO . Neural network computing. Xi'an: Xi'an Electronic and Science University press, 1995.

[14] Kai-li ZHOU, Yaohong KANG. Neural network model and MATLAB simulation program design. Beijing: Tsinghua University press, 2005.

[15] Shang-feng YAO. Design of Neural Network Based on Experiment of Orthogonality [J]. Mathematics in Practice and Theory , 38(13): 116-122, 2008 